Social norms related to combining drugs and sex ("chemsex") among gay men in South London

Ahmed AK (BSc, MSc) ${ }^{1}$, Weatherburn P (BA, MSc) $)^{1}$, Reid D (BA MSc, $)^{1}$, Hickson F (BSc, PhD, BA $)^{1}$, Torres-Rueda S (MSc, BA) $)^{2}$, Steinberg P $(B A, M A)^{3}$, Bourne A $(B S c, P h D)^{1 *}$

1. Sigma Research, Department of Social \& Environmental Health Research, London School of Hygiene \& Tropical Medicine.

2. Department of Global Health and Development, London School of Hygiene \& Tropical Medicine.

3. Department of Public Health, London Borough of Lambeth

* Corresponding author:

Dr Adam Bourne

Sigma Research

London School of Hygiene \& Tropical Medicine

15-17 Tavistock Place

London WC1H 9SH

Email: adam.bourne@lshtm.ac.uk

Tel: 02079272793

Word count (Introduction to Discussion): 5454

Word count (Abstract): 299 


\section{Social norms related to combining drugs and sex ("chemsex") among gay men in South London}

\section{Abstract}

\section{Background}

'Chemsex' refers to the combining of sex and illicit drugs, typically mephedrone, GHB/GBL, and crystal methamphetamine. While numerous studies have examined the role of illicit drugs in sexual risk taking, less attention has been paid to the broader social context and structures of their use among gay men. Given their established role in influencing health related behaviour, this study sought to examine the nature and operation of social norms relating to chemsex among gay men residing in South London.

\section{Methods}

In-depth interviews were conducted with thirty self-identifying gay men (age range 21-53) who lived in three South London boroughs, and who had used either crystal methamphetamine, mephedrone or GHB/GBL either immediately before or during sex with another man during the previous 12 months. Data were subjected to a thematic analysis. In addition, two focus groups $(n=12)$ were conducted with gay men from the community to explore group-level perceptions of drug use and chemsex.

\section{Results}

Chemsex was perceived as ubiquitous amongst gay men by a majority of participants, who additionally described a variety of ways it is arranged (including mobile apps) and a variety of settings in which it occurs (including commercial and private settings). Chemsex was associated with unique sexual permissions and expectations, although participants also described having personal boundaries with respect to certain drug and sex practices, suggesting within-group stigmatisation.

\section{Conclusion}

This study clearly documents exaggerated beliefs about the ubiquity of chemsex, shifts in the perceived normativity of certain settings and means to facilitate chemsex, and attitudes revealing stigma against certain types of chemsex and men who engage in it. There is a need for health promotion interventions to challenge social norms relating to drug use generally, and chemsex 
specifically, and for such interventions to make use of the online settings in which chemsex is often facilitated.

Keywords: Social norms, chemsex, gay men, drug use

\section{Introduction}

Gay and bisexual men are the most likely group by sexual orientation to use illicit drugs in the United Kingdom, and drug use rates for this group are highest in London (UK Home Office, 2014). Drug use is common on gay commercial scenes in several major international cities (Bauermeister, 2007; Fernandez et al., 2005; Keogh et al., 2009; Mattison, Ross, Wolfson, \& Franklin, 2001; Theodore, Duran, \& Antoni, 2014), however in London there appears to have been a recent shift in the types of drugs that are commonly used and the settings within which such use occurs. While 'club drugs' such as ecstasy or cocaine had previously been those popular (Bourne et al, 2014), there has been a rise in the proportion of gay and bisexual men presenting to drug clinics for problems related to three newer substances: mephedrone, gamma-hydroxybutyrate/gamma-butyrolactone (GHB/GBL), and crystal methamphetamine (crystal meth) (Stuart, 2013). Antidote, a LGBT drug and alcohol support service in central London, report that these three drugs featured in only 3\% of presentations in 2005 but in 85\% in 2012 (Stuart, 2013). However, use of these three drugs is far from universal. A 2012 user survey at central London sexual health service targeted at gay and bisexual men "into the harder sex scene", found $21 \%$ had used mephedrone within the last 6 months, $19 \%$ GHB/GBL, and $10 \%$ crystal meth (Scrivner, McGowan, \& Stuart, 2013).

There may have been an increase in injection drug use, known colloquially among gay men as "slamming". The proportion of gay men attending the Antidote clinic who reported intravenous use of crystal meth or mephedrone in a sexual context increased from 20\% to 80\% between 2011 and 2012 (Stuart, 2013). At the CODE Clinic in London, the proportion of crystal meth-using men injecting increased from 30\% to 80\% also between 2011 and 2012 (Kirby \& Thornber-Dunwell, 2013).

In the UK the combining of sex and drugs, in particular mephedrone, GHB/GBL, and crystal meth, is colloquially known as "chemsex". This typically involves the use of these drugs within extended sexual 
sessions involving multiple partners, which are commonly held private residences, as well as in sexon-premises venues (such as saunas and the backrooms of clubs) (Bourne, Reid, Hickson, Torres Rueda, \& Weatherburn, 2015). Chemsex has been of concern to health services across the UK, with attention concentrated in South London, home to a large commercial gay scene which has historically been associated with drug use (Measham, Wood, Dargan, \& Moore, 2011). This region of the city has a large population of gay and bisexual men (UK Home Office, 2014) and includes the largest populations of HIV-positive men in the UK (Ruf et al., 2011). That is not to say that chemsex is an issue reserved for London and indeed a 2010 community survey of MSM suggests a similar profile of chemsex associated drug use among men living in Brighton and Manchester (Schmidt et al., submission under review). Recent media reporting on chemsex has focussed on overdose, death, and HIV transmission (Cheston, 2014; Cooper, 2013; Toynbee, 2014). However, such reports overlook the heterogeneity of gay life in London and conflate evidence with perceived norms. Social norms perpetuate human behaviours which are both helpful and harmful (Berkowitz, 2004). Sunstein (1996) defines social norms as social attitudes of approval or disapproval that specify what ought and ought not to be done and are significant in the context of health because they are responsible, at least in part, for influencing individual health decisions and behaviours. Ajzen (1991) further distinguishes 'subjective norms' as the perceived social pressures to perform, or not perform, a particular behaviour. Along with attitudes and perceived behavioural control, they constitute one of three influences on behaviour (and points of possible intervention) in the Theory of Planned Behaviour (Ajzen, 1991). 'Social proof' is the perception that a certain behaviour is popular or accepted and has been proposed as a motivator to engage in a behaviour (Cialdini, Kallgren, \& Reno, 1991) since socially sanctioned opinions of approval or disapproval can override privately held beliefs (Sunstein, 1996). Crucially, the social norms approach also posits that exaggerated perceptions of the normativity of certain high-risk behaviours can perpetuate these behaviours (Berkowitz, 2004).

Social norms may have a significant influence on the health of gay and bisexual men. Prior research has demonstrated that sexual behaviour norms perpetuated by peer groups exert more influence than those arising from other sources such as family members (Gallois et al., 1992), and that norms are more influential in organised and visible gay communities than in underground ones (Fishbein et al., 1993). In a previous qualitative study, gay and bisexual men in England perceived drug and alcohol 
use as very common in certain social networks as well as an integral aspect of socialising (Keogh et al., 2009). The Keogh study is one of surprisingly few that has focussed specifically on drug use among gay and bisexual men, rather than only examining the role of drugs in sexual risk-taking behaviour, as most other research among this population has tended towards. In order to support gay and bisexual men in the safe management of drugs it is important to understand the social contexts within which drug use occurs, how new patterns of drug use propagate through gay communities, and the norms that govern their use. The current study is an attempt to further this understanding.

While drugs have been used in a sexual context by gay men (and the general population) for many years (Toates, 2014), chemsex may represent a significant development in the quality of such experiences and the proportion of the population experiencing them. Use of the three drugs associated with chemsex causes arousal, euphoria, and disinhibition, permitting multiple sexual partners, intense and adventurous sexual activity, and exposure to a greater degree of harm (Bourne, Reid, Hickson, Torres Rueda, Steinberg, et al., 2015; Bourne, Reid, Hickson, Torres Rueda, \& Weatherburn, 2014) than was the case regarding previously popular drugs such as ecstasy, MDMA and cocaine. Given this shift in drug use patterns and associated harms, research on chemsex in London is both timely and necessary: understanding how gay men in London perceive chemsex can inform the development of harm reduction interventions. A key aim of our study was to describe the nature and operation of social norms relating to chemsex among gay men in South London, and identify public health implications.

\section{Methods}

\section{Recruitment}

Between October 2013 and February 2014 we sought to recruit participants for in-depth interviews as well as two focus groups. Advertisements were placed on social networking apps for gay men and a widely read gay scene print/online magazine, and business cards were distributed in health, wellbeing, and social care settings serving gay men. The recruitment advertisements described a study about drug use during sex among gay men in South London and directed anyone who was interested to a dedicated website (www.chemsexstudy.com), This site provided detailed information about the 
study, its eligibility criteria, and a phone number, texting number, and email address through which individuals could express their interest in participating to the last author.

\section{In-depth Interviews}

Inclusion criteria for in-depth interviews were: men aged over 18 years; living in any of three South London boroughs (Lambeth, Southwark or Lewisham); who had combined sex (with another man/men) and drugs (crystal meth, GHB/GBL, and/or mephedrone) in the past 12 months. Of 44 men registering an interest in being interviewed, 9 were ineligible and 5 did not respond to follow-up emails to schedule an interview. After providing consent, 30 men took place in face-to-face interviews lasting between one and two hours. We used a semi-structured schedule and, with consent, digital recording. Topics included histories of drug use, the social and sexual contexts of drug use, perceived drug use norms, and experiences of harm and harm reduction need.

The majority of interviews took place in private interview space at the London School of Hygiene and Tropical Medicine (LSHTM) while a small number took place in private homes. Authors AB and DR, who have a combined 30 years' experience interviewing on sensitive topics, conducted interviews. All participants were compensated $£ 20$ for their time. Digital recordings of interviews were transcribed verbatim.

All participants identified as gay. For other characteristics see Table 1.

Table 1: In-depth interview sample demographic characteristics

$\begin{array}{lcll}\text { HIV testing history } & \text { N } & \text { Age } & \\ \text { Diagnosed HIV positive } & 13 & \text { Range } & 21-53 \\ \text { Last test negative } & 17 & \text { Mean } & \text { years }\end{array}$

36 years

$\begin{array}{llll}\text { Level of educational attainment } & \text { N } & \text { Ethnicity } & \text { N } \\ \text { GCSE or equivalent } & 1 & \text { White British } & 16 \\ \text { A-level or college } & 10 & \text { White Other } & 11\end{array}$




\section{Drugs use in previous 12 months}

Mephedrone

GHB/GBL

Crystal methamphetamine

Cocaine

Ketamine

\section{Injection drug use}

$23 \quad$ Never 19

22 Within last 12 months 9

$17>12$ month ago 2

\section{Focus groups}

We also hosted two focus groups of six men each $(n=12)$ to gain insight on community-level perceived norms about chemsex in London using a less-restricted sample of men. There was no requirement for focus group participants to have engaged in chemsex, although around a quarter made unprompted disclosure that they had done so recently. The inclusion of focus groups allowed for the examination of community perceptions, social norms and expectations in a manner that is harder to accomplish by individual in-depth interviews alone (Kitzinger, 1995). Questions posed to these groups centred on perceptions of drug use and chemex (rather than personal experience), and on the physical and online spaces in which they are known (or thought) to be utilised or accessed. Inclusion criteria were men aged 18+ years, living in LSL, and who had sex with a man in the last 12 months.. Focus group participants were recruited via social media and e-newsletters distributed by community-based organisations for gay men. Individuals who showed interest in participating in the in-depth interviews but had not engaged in chemsex themselves were invited to a focus group, as were those contacting the study team after the target for in-depth interviews had been reached.

All focus group participants described themselves as gay. Their other characteristics are shown in Table 2. 
Table 2: Focus group sample demographic characteristics

\begin{tabular}{|l|l|l|l|}
\hline HIV testing history & $\mathbf{N}$ & Age & \\
Diagnosed HIV positive & 1 & Range & 25-53 years \\
Last test negative & 11 & Mean years \\
\hline $\begin{array}{l}\text { London borough of residence } \\
\text { Lambeth }\end{array}$ & $\mathbf{N}$ & $\begin{array}{l}\text { Ethnicity } \\
\text { White British }\end{array}$ & 5 \\
Lewishwark & 2 & White Other & 7 \\
\hline
\end{tabular}

\section{Analysis}

Transcripts were read and coded using NVivo 10 and a thematic coding framework was established.

These were merged across transcripts to establish themes and higher order constructs, initiated by the first author and corroborated by the last.

Transcription texts were subject to a six-step inductive thematic analysis as described by Braun and Clarke (2006). Once all data sources were transcribed, data familiarisation (phase 1) was achieved by two active and immersive readings of the entire dataset. Following this, an initial list of codes was generated (phase 2), and NVivo was used to code the dataset according to this initial code list and also according to codes that were generated during subsequent readings of the dataset. In phase 3 , codes were grouped together and a rough thematic map was drawn, discarding codes which did not relate to any other codes or contained very little data. Co-authors reviewed and re-organized themes and the codes within them in phase 4. Importantly, the entire dataset was re-read following the establishment of these five themes in order to ensure that the coded data still fit within the scope of the themes, and to code any additional data to the themes that were missed during previous codings. Lastly, the five final themes were defined and named (phase 5), and this paper was produced (phase $6)$.

The study was approved by the London School of Hygiene and Tropical Medicine Ethics Committee (Ref: 6513). 


\section{Results}

As we explore in more detail in a separate paper (Bourne et al, 2015), the patterns and experience of drug use generally, and chemsex specifically, varied among the men who took part in the in-depth interviews. Some had been using a range of drugs over a long period while others had been more recently introduced to their use. While not typical in the presentation of different data sources, in this section we describe findings from both the in-depth interviews and focus groups in a combined manner. Initial analyses of social norms related data suggested considerable overlap in thematic areas. While strongly related in conceptual content, the varied perspectives of those deeply enmeshed in a chemsex 'scene' (largely the interview participants) contrasts those held by focus group participants and serve to illustrate the complexity of social processes relating to this phenomenon.

Across the interview and focus group data, four key themes were identified that engage with our aim of understanding social context and social norms: 'Ubiquity of Chemsex', 'Settings and Spaces', 'Permissions and Expectations', and 'Drawing a Line'. . Focus group data tended towards corroborating data from in-depth interviews from a community-level perspective. The first two themes discuss community-wide norms describing chemsex: how frequently men think it occurs and where they think it occurs. The second two themes concern norms that arise during chemsex, including men's perceptions and attitudes about the acceptability of various chemsex-related behaviours and activities, and how norms differ depending on the characteristics of the participants.

\section{Ubiquity of Chemsex}

Most men we interviewed perceived drug use as a common and normalised behaviour among gay men in south London, being highly visible in physical venues and discussed on geospatial networking apps. When asked how common it was to take drugs on the gay scene, over half stated very common or estimated that $70-90 \%$ of the gay male population of South London take drugs. Focus group participants agreed. 
“Rampant. It's just everywhere. I mean, even if you go to - you think - no, it's everywhere. I mean, I can't think of anywhere where l've not seen drugs being taken. Yeah, that's the reality." [Aged 31, last tested HIV negative]

Chemsex specifically was also perceived as commonplace by interviewees. Focus group participants, only some of whom engaged in chemsex, expressed the same view. In contrast, a few men perceived drugs and chemsex to be minority behaviours, stating that it was prevalent only within certain social circles or networks.

"That's a portion of the gay scene. That is a limited number of people and there are a lot of gay men out there who aren't into that at all. Who don't give a fuck. Who wouldn't even consider it and who, when you start telling them about this, are absolutely mortified that this kind of thing happens." [Aged 32, last tested HIV negative]

A third of men interviewed, as well as some focus group members, mentioned that chemsexassociated drugs were readily available. Although still in use by some, drugs such as cocaine, ketamine, and ecstasy/MDMA were mentioned infrequently. Drugs could be accessed through several means, with some participants perceiving an increase in drug dealers both inside and outside nightlife venues and on mobile geospatial apps that cater for gay men. When discussing the pervasiveness of drug use, men overwhelmingly spoke about drug use in sexual settings. Just under a third of men who were interviewed stated that they believed drug use and sex to be inextricable. Others claimed that drug use in social settings like clubs will usually lead to sex or that they now used drugs exclusively to facilitate sex.

\section{Settings and Spaces}

Changes in the patterns of drugs used are accompanied by shifts in the settings in which chemsex is arranged and occurs. Men identified and differentiated between multiple chemsex settings. Nearly all participants, including those interviewed and around half of those in focus groups, used chemsexassociated drugs in nightclubs and perceived that the majority of club-goers did as well. Most clubgoing interview participants narrated a progression of events that involved using drugs (most popularly mephedrone) in clubs but moving to private residences at the end of the night to engage in 
chemsex. Drug use generally, and chemsex specifically, was frequently reported or perceived to occur in commercial spaces, and saunas were sometimes constructed as a bridging point between largely social (clubs) and primarily sexual spaces (private homes).

Importantly, however, chemsex hook-ups could be arranged online and occur without any need to patronise commercial venues. Just over one-third of interviewees (as well as members of both focus groups) talked about the perceived waning popularity of clubs and the increasing popularity of private parties as settings for chemsex. Attendance at sex parties (sometimes referred to as 'chill outs') was believed to be as commonplace as club attendance among the interview sample.

"And it started to become, "We're paying twenty quid to get into a place. Why not have drugs at home, with a sex party?" You know, this is the alternative; and we've got apps that can help to facilitate that need, and make that happen [...] People stay long hours being very bored in clubs and bars, sometimes, and all they wanted was just a shag. So that just helps to facilitate their, almost immediate needs of chasing that orgasm." [Aged 31, last tested HIV negative]

Many men who discussed chemsex in private settings (sex parties) attributed its increased popularity to mobile geospatial networking applications (apps). A particular app, or apps in general, were mentioned in the majority of interviews and in both focus groups, and were perceived as an established and accepted virtual space in which to arrange chemsex. By facilitating these encounters, apps contributed to the dwindling need for physical settings, such as bars and clubs, to meet men and buy drugs.

“They didn't need to go out clubbing, so I think there's definitely been, and then you add to that [app], which means that people don't need to go out to meet people. [...] because we're all living in Lambeth so we all fucking know each other. We can all get each other on [app]. There's a dealer there, there, there and there. We don't need the clubs." [Aged 32, last tested HIV negative]

Private settings such as homes and hotel rooms were commonly perceived as safe and accepted venues for men to engage in chemsex. The shift into private domains may be attributed in part to a 
desire to engage in stigmatised and/or high-risk drug and sexual behaviours, including use of crystal meth, perhaps smoking and injecting, which is impractical in clubs. Interviewees nearly always described their own crystal meth use and IDU as occurring in private settings as opposed to public venues. A small number of interviewees and a few focus group members spoke of sex parties as a normalised environment for HIV positive men to engage in unprotected anal intercourse chemsex and injection drug use.

\section{Permissions, expectations and initiations}

Many men perceived that the sexual experiences sought and expected in chemsex were different from other sex. Certain acts were felt to be more permissible when taking place in the contexts of chemsex. About one-in-six interviewees and some focus group participants described a culture of men pushing themselves to their sexual and drug use limits.

"I think it's the danger with sex at sex parties and all the fun things, you always want to put the bar up higher to get a higher satisfaction as well. And sometimes, yeah, sometimes it goes too far." [Aged 31, last tested HIV negative]

Many participants also described what might be considered an economy of drug use in sexual settings, with expectations around how and why sex and sexual partners may change when drugs are present. A small number of interviewees and some focus group participants reported engaging in sex under the influence of drugs that might otherwise have been considered taboo or unlikely in non-drug settings. These men spoke about a shifting of standards during chemsex; they themselves, or men that they knew, would exchange drugs for sex with a younger/more attractive man, or exchange sex with an older/less attractive man for drugs.

"And finding it very easy getting young boys to come round because as soon as you mention l've got tina, lads are round like a shot. Absolutely. I've got a friend who's a lovely person but probably not the best looking bloke in the world but he's got loads of tina and whenever I drop in for coffee or a slam in the recent past he'd have the most beautiful men round because he's got drugs to give away." [Aged 48, diagnosed HIV positive] 
In this regard, the supply of drugs comes with the expectation of sexual activity, and their consumption permits men to have sex with those they would not consider as partners if sober. Drugs are both one side of a transaction and the transaction's facilitator.

Participants frequently drew upon a commonly accessible discourse around the disinhibiting effects of drugs to help rationalise their actions, particularly as they pertained to risky sexual practices or involved more esoteric sexual behaviours. Phrases such as 'Being carried away with the moment', 'not caring as much', and 'feeling more reckless' were used throughout the interviews in a manner that allowed them to make sense of their experience without necessarily having to describe it in detail. The phenomenon of chemsex is not unique in this regard but it is crucial to acknowledge given that chemsex is often regarded by the media (eg. Anonymous, 2015; Knapton, 2015) as a causative factor in HIV transmission risk behaviour when in fact there may be a range of other factors that influence risky sex, but which are harder to articulate than this common drug use discourse (Weatherburn, Hickson, Reid, Torres-Rueda, \& Bourne, 2016submission under review).

Such normative discourse was also a feature of drug use and chemsex initiation narratives. A significant proportion of the men who took part in interviews described how they had cycled through the full range of drugs that had been popular on the gay scene over the past one or two decades. The more recent use of drugs associated with chemsex was presented as a natural, normative progression of drug use that was occurring among all gay men. For others, sexual partners, most often identified on sexual networking applications, made introduction to drugs and to chemsex. A belief held by several focus group participants, but actually reported by only a few interviewees, was that initiation into chemsex was typically as a result of stressful life events, such as a relationship breakup or the receipt of a HIV positive diagnosis.

\section{Drawing a Line}

Despite the relative sexual freedom afforded by drugs, men in interviews often attempted to establish personal boundaries regarding certain chemsex-associated behaviours. These boundaries included the frequency or intensity of drug use and chemsex, crystal meth use, and injection drug use, and were often formed by observing the behaviour of others. One-fifth of interviewees described knowing 
or seeing other men whom they believed had lost control of their lives due to excessive drug use and chemsex. Equally, participants described how they, as recreational users, had successfully compartmentalised chemsex from the rest of their lives, while others, more problematic users, were perceived to have allowed chemsex to infiltrate and dominate their lives.

"It's like - a lot of people, I know they were in complete denial of how much the drugs were affecting their life. [...] They're like - it's fine, it's fine; I'm still doing my job, and I've only called in sick three times this month. I'm like - it is affecting your life. Oh - I missed my mum's funeral. Like - what? People - it is affecting their lives." [Aged 21, last tested HIV negative]

Often men would differentiate between what they perceived as their own controlled habits and the more extreme habits of others. This act of viewing the behaviours of others as more extreme existed, for some men, towards injection drug use as well. While one-third of interviewees had experience of injecting, another quarter (and some focus group participants) expressed an apprehension or distaste towards IDU. Some explicitly stated that slamming or use of crystal meth were lines that they would never cross. Others expressed a belief that establishing a boundary between slamming and other methods of drug use was not just a personal choice, but a community-wide division:

"I think there's two levels [...] for my point of view in the scene l'm in, it's mainly $G$ and meph together, mephedrone; and the ones that do that as a starter, but slam Tina a lot. So I think that - when you are in chemsex, you are asked if you do Tina, you will be in one group; if you do mephedrone you will be in that group." [Focus group participant]

At the same time, about one-sixth of interviewees and multiple focus group members expressed a belief that slamming had recently become more common and accepted, with two describing slamming as "trendy". Still, many men in the present sample who acknowledged the growing popularity of IDU enforced self-imposed boundaries that prevented them from doing it. Reasons for not injecting included perceived dangerousness of the activity, its connotations with heroin addiction, perceived lifestyle chaos and crime, and not wanting to progress to a new level of drug activity leading to dependency and loss of control. 
Another perceived axis of extremity was HIV status. Many men believed that HIV-positive men were more likely to engage in high-risk sex and drug behaviours. Participants in both focus groups and one-in-six interviewees (including two HIV-positive men) thought slamming, crystal meth use, and unprotected anal intercourse were normalised among HIV-positive men on the chemsex scene. This was attributed to a "nothing left to lose" attitude.

"I've said it myself, and l've heard friends say it about HIV positives, as well - that they've got a lot less to lose [...] Although l'm quite healthy, I certainly can't contract HIV again. [...] I'm in the situation where I could be a little bit more free to experience what I want to experience." [Aged 28, last tested HIV positive]

While HIV-positive men have been reported as more likely to use crystal meth and engage in IDU than HIV-negative men (Bonell, Hickson, Weatherburn, \& Reid, 2010; Bourne et al., 2014; Carey et al., 2009; Forrest et al., 2010) it is also the case that both are minority behaviours among men with diagnosed HIV.

\section{Discussion}

Chemsex was perceived by a majority of participants as a normalised behaviour among gay men in South London. This normalisation was established through the perceived ubiquity of drug use generally, but more specifically drug use for sex. The perception that most gay men in South London are participating in chemsex contradicts survey data measuring its actual prevalence. Among a large but opportunistic sample of gay/bisexual men living in England in 2014 ( $n=15,360), 8.3 \%, 16.5 \%$, and $12.5 \%$ had ever used crystal meth, mephedrone, and GHB/GBL respectively, and 2.0\%, 5.3\%, and $3.2 \%$ had used each drug within the past four weeks (Hickson, Reid, Hammond, \& Weatherburn, 2016). Similarly, while only $1.8 \%$ of men in this survey had injected drugs (other than anabolic steroids or prescribed medicines) within the previous 12 months, many men in this survey perceived it as increasingly common in gay communities. It is important to highlight data indicating a higher prevalence of drug use among MSM living in London compared to the national prevalence estimate (e.g. crystal methamphetamine use of $11.1 \%$ within the previous 12 months among men in London, compared to between 2\% and 3\% of men elsewhere in England), although even these figures do not indicate the level of ubiquity that men within the current qualitative study often perceived. 
Berkowitz's (2004) social norms approach suggests that an individual's false perceptions about how members of their social groups think and act can lead to an overestimation of certain behaviours (termed the "false consensus effect"), and therefore encourage individuals to engage in these behaviours themselves. According to this theory, talking up risk behaviours becomes a self-fulfilling prophecy. Thus, misperceptions regarding the ubiquity of chemsex could conceivably play a role in increasing rates of drug use or injecting practice among gay men in London if, indeed, that is the case. Social norms interventions (Berkowitz, 2004) focus on correcting false consensus by providing believable information on actual behaviours (what members of a group actually do). A social norms intervention in London could potentially attend to misperceptions regarding the ubiquity of chemsex (Berkowitz, 2004; Cialdini et al., 1991).

Our data indicate the continued popularity of drug use on the commercial gay scene in London and a need for maintaining or expanding harm reduction measures in these spaces. At the same time, men endorsed sex parties and chill-out parties as cheaper, safer and easier venues to engage in chemsex in. There was also some evidence to suggest that high-risk sexual practices such as unprotected anal intercourse and intravenous drug use were more normalised in private settings. Use of mobile apps was pervasive among the sample and explicitly facilitated drug purchases and arrangement of sexual encounters. These apps may be a promising avenue through which health promotion for chemsex in private settings may be implemented.

Chemsex differed from sober sex both in terms of what was permitted and what was expected. The greater sexual permissiveness and variety of partners that is normative of chemsex has the potential of both physical and mental harm as well as to increase pleasure and sexual satisfaction. This risk of harm may be pronounced among more highly stigmatised subsets of men, such as injection drug users and those who use crystal meth, the stigmatisation of who has been documented elsewhere (Kirby \& Thornber-Dunwell, 2013). Participants in this study also compartmentalised themselves from other men on the basis of HIV status, with some expressing a perception that high-risk practices such as unprotected anal intercourse and IDU were more normalised among HIV-positive men. This speaks to the wider sense of stigma and discrimination that HIV-positive gay men often experience 
from their HIV-negative counterparts (see Smit et al. (2012) for a review). Although such attitudes may be protective for the health of men who 'draw a line' at high-risk behaviours, they can further marginalise those who do not. Literature on HIV stigma suggests that this experience of 'othering' (Miller, 2008) is associated with adverse health outcomes, exacerbation of high-risk behaviour, and lower rates of HIV status disclosure, testing, and service utilisation for HIV-positive men (Smit et al., 2012).

Community-based health promotion may be a relatable and inclusive means of reaching stigmatised subgroups of gay men and mitigating chemsex harms (Keogh et al., 2009). Messages delivered by members from one's own peer group are often perceived as the most influential (Hamilton \& Mahalik, 2009; Hornstein, Fisch, \& Holmes, 1968) Indeed, engagement with LGBT communities and community-level interventions have been recommended elsewhere (Clark, 2013; Keogh et al., 2009; Kurtz, 2005; Stuart, 2015). Chemsex interventions should also actively attempt to prevent further stigmatisation of gay and bisexual men, especially considering recent media sensationalism regarding the perceived public health burden of chemsex (Holt, 2014).

Although we did not specify HIV status in the recruitment criteria for this study, it is notable that 13 of our 30 chemsex participants had diagnosed HIV but only one of the 12 community members taking part in the focus groups was living with diagnosed HIV. This may have conflated social norms expressed by gay men with diagnosed HIV (where published data suggests a higher prevalence of chemsex associated drug use (Bourne et al., 2014)) with those of all gay men engaged in chemsex. However, our analysis did not reveal any significant points on which interviewees and focus group members disagreed.

This study reports findings from a convenience-sampled qualitative study within a contained geographical area of South London, however the rapid transport and inter-connectivity of gay men across London suggests the findings may reflect the perspectives and experiences of men in the city more broadly. London has a significant gay population and gay commercial scene and this should be taken into account when considering how the findings have relevance in other settings. Chemsex is a relatively new cultural phenomenon in the UK, but there are signs of similar drug use behaviours 
arising in other parts of Europe (Fourer et al., 2014; Knoops, Bakker, van Bodegom, \& Zantkuijl, 2015). Over the last two years there has been considerable media and political attention brought to bear on the issue. Future research may wish to examine patterns and contexts over longer periods of time, attending to such community and national level discourses and the ways in which these influence perceptions, engagements and responses to chemsex.

Findings from this study suggest that there is not one homogenous chemsex scene nor one set of norms that governs it. Rather, men implicitly and explicitly categorise themselves and others on the basis of drugs used, frequency and intensity of use, injecting, and HIV status. Given the significant level of media reporting and political commentary on this issue, there may be important roles for health promotion interventions in challenging social norms relating to drug use, especially those that support a sense of ubiquity, and the sub-group stigmatisation of those who choose to engage in chemsex. Such stigma can do little to improve the access to, or uptake of, services that help to minimise the harms associated with drug use, in all its forms.

\section{Acknowledgements}

This research was commissioned and funded by the London Boroughs of Lambeth, Southwark and Lewisham. We wish to thank all the community-based organisations who helped recruit to, or host, the interviews and focus groups, and all of the men who gave up their time to take part.

\section{References}

Ajzen, I. (1991). The Theory of Planned Behaviour. Organizational Behaviour and Human Processes, $50,179-211$

Anonymous. (2015, 12 November 2015). Drug-fuelled 'chemsex' party survivor: I woke up naked on the sofa - I had no idea where I was. London Evening Standard.

Bauermeister, J. A. (2007). It's all about "connecting": reasons for drug use among Latino gay men living in the San Francisco Bay Area. J Ethn Subst Abuse, 6(1), 109-129. doi: 10.1300/J233v06n01_07

Berkowitz, A. D. (2004). The Social Norms Approach: Theory, Research, and Annotated Bibliography. 
Bonell, C. P., Hickson, F. C., Weatherburn, P., \& Reid, D. S. (2010). Methamphetamine use among gay men across the UK. International Journal of Drug Policy, 21(3), 244-246. doi: 10.1016/j.drugpo.2009.07.002

Bourne, A., Reid, D., Hickson, F., Torres Rueda, S., Steinberg, P., \& Weatherburn, P. (2015). "Chemsex" and harm reduction need among gay men in South London. International Journal of Drug Policy. doi:10.1016/j.drugpo.2015.07.013

Bourne, A., Reid, D., Hickson, F., Torres Rueda, S., \& Weatherburn, P. (2014). The Chemsex study: drug use in sexual settings among gay \& bisexual men in Lambeth, Southwark \& Lewisham: Sigma Research, London School of Hygiene and Tropical Medicine.

Bourne, A., Reid, D., Hickson, F., Torres Rueda, S., \& Weatherburn, P. (2015). Illicit drug use in sexual settings ('chemsex') and HIV/STI transmission risk behaviour among gay men in South London: findings from a qualitative study. Sex Transm Infect. doi:10.1136/sextrans-2015052052

Braun, V., \& Clarke, V. (2006). Using thematic analysis in psychology. Qualitative Research in Psychology, 3(2), 77-101. doi: 10.1191/1478088706qp063oa

Carey, J. W., Mejia, R., Bingham, T., Ciesielski, C., Gelaude, D., Herbst, J. H., . . Stall, R. (2009). Drug use, high-risk sex behaviors, and increased risk for recent HIV infection among men who have sex with men in Chicago and Los Angeles. AIDS Behav, 13(6), 1084-1096. doi: $10.1007 / \mathrm{s} 10461-008-9403-3$

Cheston, P. (2014, 24 June 2014). Three men die within months of each other after taking party drug at London gay sauna. London Evening Standard.

Cialdini, R. B., Kallgren, C. A., \& Reno, R. R. (1991). A focus theory of normative conduct: a theoretical refinement and reevaluation of the role of norms in human behaviour. Advances in Experimental Social Psychology, 24, 201-234.

Clark, C. (2013). A health needs assessment for men who have sex with men (MSM) in Lambeth. London: Lambeth Clinical Commissioning Group.

Cooper, C. (2013, 25 July 2013). Party drugs linked to alarming rise in HIV amongst gay men. The Independent.

Fernandez, M. I., Bowen, G. S., Varga, L. M., Collazo, J. B., Hernandez, N., Perrino, T., \& Rehbein, A. (2005). High rates of club drug use and risky sexual practices among Hispanic men who 
have sex with men in Miami, Florida. Subst Use Misuse, 40(9-10), 1347-1362. doi: 10.1081/JA-200066904

Fishbein, M., Chan, D. K. S., O'Reilly, K., Schnell, D., Wood, R., Beeker, C., \& Cohn, D. (1993). Factors influencing gay men's attitudes, subjective norms, and intentions with respect to performing sexual behaviors. Journal of Applied Social Psychology, 23(6), 417-438.

Forrest, D. W., Metsch, L. R., LaLota, M., Cardenas, G., Beck, D. W., \& Jeanty, Y. (2010). Crystal methamphetamine use and sexual risk behaviors among HIV-positive and HIV-negative men who have sex with men in South Florida. Journal of Urban Health, 87(3), 480-485. doi: $10.1007 / \mathrm{s} 11524-009-9422-\mathrm{z}$

Fourer, N., Fournier, S., Jauffret-Routside, M., Labrouve, V., Pascal, X., Quatremere, G., \& Rojas Castro, D. (2014). Slam: Premiere enquete qualitative en France. Paris: AIDES \& INSERM.

Gallois, C., Kashima, Y., Terry, D., Mcamish, M., Timmins, P., \& Chauvin, A. (1992). Safe and unsafe sexual intentions and behavior: The effects of norms and attitudes. Journal of Applied Social Psychology, 22(19), 1521-1545.

Hamilton, C. J., \& Mahalik, J. R. (2009). Minority stress, masculinity, and social norms predicting gay men's health risk behaviors. Journal of Counseling Psychology, 56(1), 132-141. doi: $10.1037 / \mathrm{a} 0014440$

Hickson, F., Reid, D., Hammond, G., \& Weatherburn, P. (2016). State of play: findings from the England Gay Men's Sex Survey 2014: Sigma Research, London School of Hygiene \& Tropical Medicine.

Holt, M. (2014). Sex, drugs, and HIV: let's avoid panic. The Lancet HIV, 1(1), e4-e5. doi: 10.1016/s2352-3018(14)70007-4

Hornstein, H. A., Fisch, E., \& Holmes, M. (1968). Influence of a model's feelings about his behaviour and his relevance as a comparison other on observers' helping behaviour. Journal of personality and social psychology, 10, 220-226.

Keogh, P., Reid, D., Bourne, A., Weatherburn, P., Hickson, F., Jessup, K., \& Hammond, G. (2009). Wasted opportunities: Problematic alcohol and drug use among gay men and bisexual men. London: Sigma Research, London School of Hygiene and Tropical Medicine.

Kirby, T., \& Thornber-Dunwell, M. (2013). High-risk drug practices tighten grip on London gay scene. The Lancet, 381(9861), 101-102. doi: 10.1016/s0140-6736(13)60032-x 
Kitzinger, J. (1995). Qualitative research: Introducing focus groups. BMJ, 311, 299.

Knapton, S. (2015, 3 November 2015). Chemsex: the alarming new trend of 72 hour drug-fuelled sex sessions. The Telegraph.

Knoops, L., Bakker, I., van Bodegom, R., \& Zantkuijl, P. (2015). Tina and slamming: MSM, crystal meth use and injecting drugs in a sexual setting. Amsterdam: Mainline \& SOAIDS.

Kurtz, S. P. (2005). Post-circuit blues: motivations and consequences of crystal meth use among gay men in Miami. AIDS Behaviour, 9(1), 63-72. doi: 10.1007/s10461-005-1682-3

Mattison, A. M., Ross, M. W., Wolfson, T., \& Franklin, D. (2001). Circuit party attendance, club drug use, and unsafe sex in gay men. Journal of Substance Abuse, 13, 119-126.

Measham, F., Wood, D. M., Dargan, P. I., \& Moore, K. (2011). The rise in legal highs: prevalence and patterns in the use of illegal drugs and first- and second-generation "legal highs" in South London gay dance clubs. Journal of Substance Use, 16(4), 263-272. doi: $10.3109 / 14659891.2011 .594704$

Miller, J. (2008). Otherness. In L. M. Given (Ed.), The SAGE Encyclopedia of Qualitative Research Methods (Vol. 2, pp. 588-591). Thousand Oaks, CA: SAGE Publications, Inc.

Ruf, M., Delpech, V., Osuagwu, U., Brown, A. E., Robinson, E., \& Chadborn, T. (2011). Men who have sex with men: estimating the size of at-risk populations in London primary care trusts. Int J STD AIDS, 22(1), 25-29. doi: 10.1258/ijsa.2010.010181

Schmidt, A., Bourne, A., Weatherburn, P., Reid, D., Marcus, U., \& Hickson, F. Illicit drug use among gay and bisexual men in 44 cities: finding from the European MSM Internet Survey (EMIS) (submission under review).

Scrivner, J., McGowan, A., \& Stuart, D. (2013). Recreational Drug Use amongst GUM Attendees Implications for Service Delivery. Poster presented at 19th Annual British HIV Association Conference. Manchester.

Smit, P. J., Brady, M., Carter, M., Fernandes, R., Lamore, L., Meulbroek, M., . . Thompson, M. (2012). HIV-related stigma within communities of gay men: a literature review. AIDS Care, 24(4), 405-412. doi: 10.1080/09540121.2011.613910

Stuart, D. (2013). Sexualised drug use by MSM: background, current status and response. HIV Nursing, Spring, 6-10.

Stuart, D. (2015). Chemsex in the city - it's every gay man for himself. FS Magazine, 149. 
Sunstein, C. R. (1996). Social Norms and Social Roles Working Paper No. 36: Coase-Sandor Institute for Law \& Economics.

Theodore, P. S., Duran, R. E., \& Antoni, M. H. (2014). Drug use and sexual risk among gay and bisexual men who frequent party venues. AIDS Behaviour, 18(11), 2178-2186. doi: 10.1007/s10461-014-0779-y

Toates, F. (2014). How Sexual Desire Works: The Enigmatic Urge. Cambridge: Cambridge University Press.

Toynbee, P. (2014, 27 May 2014). Drug experts issue warning over 'chem-sex' parties. The Guardian. UK Home Office. (2014). Drug Misuse: Findings from the 2013-14 Crime Survey for England and Wales. Section 4. Estimates of illicit drug use by ethnicity and sexual orientation. Retrieved from http://www.gov.uk/government/publications/drug-misuse-findings-from-the2013-to-2014-csew.

Weatherburn, P., Hickson, F., Reid, D., Torres-Rueda, S., \& Bourne, A. (2016). Motivations and values associated with combining sex and illicit drugs ('chemsex') among gay men in South London: findings from a qualitative study. Sex Transm Infect. doi: doi:10.1136/sextrans-2016052695 